\title{
ASPECTOS LEGAIS AMBIENTAIS E SUA INFLUÊNCIA NOS CUSTOS DA ATIVIDADE MINERÁRIA DE BAUXITA: O EXEMPLO DA ALCOA, POÇOS DE CALDAS (MG), BRASIL
}

\section{LEGAL ENVIRONMENTAL ASPECTS AND ITS INFLUENCE OVER THE COSTS OF BAUXITE MINING: THE EXAMPLE OF ALCOA, POÇOS DE CALDAS (MG), BRAZIL}

\section{Camargo, S. A. F. de ${ }^{1}$; Surgik, A. C. S. ${ }^{2}$}

${ }^{1}$ Programa de Pós-Graduação em Direito Ambiental da Universidade do Estado do Amazonas/UEA. Rua Leonardo Malcher, 1778, 5 . Andar, Centro, CEP: 69010-170, Manaus (AM). e-mail: safc@uea.edu.br

${ }^{2}$ Programa de Pós-Graduação em Ecologia do Instituto Nacional de Pesquisas da Amazônia/INPA.

\section{RESUMO}

A atividade de mineração é regulamentada em níveis. Além dos dispositivos legais em nível federal, a legislação ambiental estadual de Minas Gerais é mais restritiva e exigente, onerando a atividade através do estabelecimento de obrigações que visam à proteção ambiental. De acordo com o Departamento de Mineração da Companhia Geral de Minas (CGM/Alcoa Alumínio S.A.), desde 1979 tem sido realizada reabilitação de áreas mineradas em Poços de Caldas. No entanto, estimativas anteriores da empresa sobre recursos financeiros, humanos e demais tipos de insumos não distinguiam os gastos com a reabilitação de áreas degradadas. Por isso, foi realizada uma pesquisa entre 2000 e 2001, com o objetivo de auxiliar o processo de tomada de decisões sobre a alocação de recursos em projetos de reparação de danos ambientais. Especificamente, buscou-se: a) descrever o contexto legal em que a atividade de mineração de bauxita se insere e; b) estimar os custos de reabilitação de áreas degradadas. Foi identificado que as estimativas de gastos com reabilitação de áreas degradadas está abaixo do que é efetivamente praticado pela empresa, por ausência de documentação contábil distinta para as atividades praticadas no setor ambiental.

Palavras-chave: Direito Ambiental, mineração, custos para a reabilitação de áreas degradadas, Alcoa Alumínio S/A. 


\section{ABSTRACT}

The mining activity is regimented mainly in two levels. The regulatory stands are distributed in federal and provincial levels. In this case, provincial environmental law (of Minas Gerais) is more restrictive, shifting mining activity costs through the statement of obligations related to environmental protection. According to the Mining Department of Companhia Geral de Minas (CGM/Alcoa Alumínio S/A), since 1979 it has been performed the rehabilitation of mined areas in Poços de Caldas. Despite this fact, CGM/Alcoa Alumínio S/A previous estimative about the budget, technical support and other material resources did not distinguish the financial needs related to the rehabilitation of mined areas. In this context it was performed a research between 2000 and 2001, aiming to subsidize the budgetary planning on financial resources allocation to the rehabilitation of mined areas, in particular: a) to describe the legal context related to the bauxite mining and; b) to estimate the costs of mined areas rehabilitation. In the conclusion, it was identified that the previous costs estimative of CGM/Alcoa Alumínio S/A is under the real level. Possibly, it occurred due to the lack of environmental activities accounting documentation.

Key words: Environmental Law, mining, rehabilitation of mined areas costs, Alcoa Alumínio S/A.

\section{INTRODUÇÃO}

Conforme o texto constitucional (art. $225, \S 2^{\circ}$ da $\mathrm{CF} / 88$ ), a mera exploração mineral, realizada por pessoa física ou jurídica, já é degradação e deve ser recuperada (MACHADO, 2005). Não há mais alternativa de indenização como trazia a Lei 6.981/81. Portanto, a reabilitação é indispensável, sendo dever do órgão público exigí-la na forma da lei. A mineração é uma atividade econômica altamente impactante ao meio ambiente. Apesar disso, suas conseqüências podem ser minimizadas em três momentos distintos: a) antes do licenciamento da atividade, através do Estudo Prévio de Impacto Ambiental (EPIA); b) durante o funcionamento do empreendimento (Auditoria) e; c) pela recomposição posterior à lavra, conforme previsão constitucional (MACHADO, 2005). No Brasil, a mineração é a atividade econômica mais controlada pela legislação ambiental e a única citada nominalmente em vários dispositivos de proteção do meio ambiente presentes na $\mathrm{CF} / 88$ (HERRMANN, 1992).

A legislação influencia a tomada de decisão do empreendedor na redução de custos com recuperação ambiental, quando o incentiva a adotar tecnologias mais limpas em função do princípio poluidor-pagador. A referência Mas (2002) identifica que nos EUA, $10 \%$ a $20 \%$ dos custos das empresas é repassado para o controle ambiental, e que a adequação das empresas de mineração às mudanças legais custou cerca de U\$ 10 bilhões para aquelas que operam em terras públicas. 
Em um segundo momento, no processo de licenciamento, o empreendedor é obrigado a apresentar medidas mitigadoras para eventuais danos ambientais da atividade para se instalar (LI) e para operar (LO). Hilson e Potter (2005) destacam estudo do World Bank que indica que a maioria dos casos de licenciamento de mineração nos países em desenvolvimento estão associados a altos custos pela complexidade de procedimentos administrativos, falta de regulamentos claros ou instituições fracas no monitoramento. Prado Filho e Souza (2004) ressaltam diversas falhas no processo de licenciamento prévio de empreendimentos minerais do Quadrilátero Ferrífero de Minas Gerais, indicando a carência de maior atenção e regulamentação dos órgãos encarregados do licenciamento ambiental.

Portanto, a adequação da empresa às exigências legais representa ônus financeiro. A Declaração do Rio de Janeiro (Conferência das Nações Unidas para o Meio Ambiente e o Desenvolvimento, 1992), reforça o incentivo ao governo em promover a internalização dos custos ambientais e o uso de instrumentos econômicos, sem distorcer o comércio e os investimentos internacionais ${ }^{1}$ (Princípio 16).

Neste processo produtivo industrial, a matéria prima passa a ter valor monetário. Na formação do lucro, os custos para a proteção ambiental decorrentes das exigências legais de proteção ao meio passam a integrar os balanços contábeis.

Neste contexto, a fim de ilustrar o impacto financeiro das exigências legais ambientais em um processo produtivo industrial, será examinado um caso prático: a mineração de bauxita pela Alcoa Alumínio S/A, em Poços de Caldas (MG). O presente estudo identifica apenas os custos estimados com a reabilitação de áreas degradadas. Não foi abordada a questão do passivo ambiental global da empresa por falta de séries temporais de dados.

De acordo com relatório interno do Departamento de Mineração da CGM/Alcoa Alumínio S.A. (Controle de Áreas Reabilitadas), desde 1979 a empresa vem realizando a reabilitação de áreas mineradas em Poços de Caldas, MG. A reabilitação consome recursos financeiros, humanos e diversos tipos de insumos, representando uma parcela do custo final da tonelada de bauxita seca. No entanto, estimativas anteriores da empresa sobre recursos financeiros, humanos e tipos de insumos não distinguiam os gastos com a reabilitação de áreas degradadas, consultorias ambientais para elaboração de estudos, desenvolvimento de métodos de mitigação de impactos, obtenção e manutenção de certificação ambiental, entre outros. Eynon e Stevens (1996) demonstram a importância ética da contabilidade dos resíduos e responsabilidade ambiental das empresas, e indicam estudo da "Price Waterhouse" que nos EUA, 62\% das empresas participantes da pesquisa não possuem sistema financeiro acurado e devidamente separado para a aplicação da responsabilidade ambiental de suas atividades.

$\mathrm{Na}$ empresa em estudo, o valor estimado empiricamente pela empresa até janeiro de 2001, era de U\$ 0,50/t de bauxita (Charles Ferreira, engenheiro da CGM/Alcoa Alumínio S.A., comunicação pessoal). No entanto, estudos sobre

\footnotetext{
${ }^{1}$ Disponível em http://www.silex.com.br/leis/normas/declaracaorio.htm (acessado em 11/05/2005).
} 
impacto de mineração realizados na Índia indicaram que para cada tonelada de bauxita extraída, são produzidas 12 toneladas de rejeito (DESHPANDE e SHEKDAR, 2005).

As estimativas de custos, diferenciadas por estratégias de reabilitação e revegetação, podem ser importantes instrumentos auxiliares no processo de tomada de decisões. Partindo-se deste ponto, a otimização da alocação de recursos às práticas de mitigação de impactos ambientais legalmente exigidas, pode facilitar o gerenciamento interno da empresa nas questões ambientais e a formulação de uma política institucional de acordo com as normas e padrões exigidos para certificação de qualidade ambiental (e.g. ISO 14000). Lightbody (2000) aponta a auditoria como importante prática no mundo industrializado no processo de adequação da contabilidade ambiental, através do relato dos impactos ambientais da atividade.

Com isso, o objetivo do estudo é identificar os procedimentos legais de licenciamento ambiental para atividades minerárias no Estado de Minas Gerais, estimando os custos totais decorrentes dessas exigências, com base em estudo de caso sobre a Alcoa Alumínio S/A. Especificamente, pretende-se: a) esboçar o contexto jurídico a que a atividade mineradora de bauxita se submete em Minas Gerais; b) identificar as variáveis jurídico-econômicas que instituem gastos ao empreendedor, no processo de reabilitação de áreas mineradas; c) rastrear e organizar os custos de reabilitação de áreas degradadas, pela extração de bauxita, nos anos de 1997, 1999 e 2000 e; d) estimar os custos totais de reparação.

\section{MÉTODOS}

\subsection{Levantamento, Análise e Aplicabilidade da Legislação}

Foram identificadas as legislações (lato sensu) sobre o tema. A busca da legislação federal foi feita através de palavras-chave no site do Planalto em Brasília, e a legislação estadual foi obtida nos sites do governo de Minas Gerais e no setor jurídico da empresa em estudo. A pesquisa legal objetivou identificar a unidade de intenções das leis, verificando se as mesmas respeitam a hierarquia das normas e se seus textos são descritos de forma a promover sua efetividade e aplicabilidade.

Este trabalho é eminentemente jurídico-teórico de coleta de legislação e interpretações como forma de subsidiar a implementação da lei. Em função disso, optou-se, por acrescentar a discussão conjuntamente com os resultados.

\subsection{Levantamento de Dados sobre Custos para Reabilitação de Áreas Degradadas}

Em dezembro de 1999, foram identificados os contatos iniciais do setor competente da empresa, a forma de apresentação dos relatórios contábeis e os protocolos de acesso aos dados (relatórios anuais da Controladoria, controles internos de produção do Departamento de Mineração da CGM/Alcoa Alumínio S.A. e arquivos contendo os comprovantes fiscais da contabilidade). 
Em janeiro de 2000, realizou-se a identificação de todos os gastos que poderiam eventualmente representar custos ambientais entre 1997 e 1999. Em seguida, todas estas informações foram aferidas através do exame dos documentos fiscais arquivados na empresa. Com isto, foram apurados exatamente os "gastos com reabilitação de áreas degradadas" e demais insumos e serviços destinados à execução de atividades de preservação ambiental, conforme previsões legais. Foram encontrados dados com as seguintes rubricas: combustíveis, serviços prestados por pessoas jurídicas, manutenção de veículos (mão de obra), fretes, materiais de manutenção de veículos, outras despesas (revelação de filmes fotográficos) e suprimentos (sementes, equipamentos, etc.). Estes gastos selecionados e comprovados foram inseridos em nova planilha para a análise de dados.

Ainda durante o levantamento de dados foi possível obter um controle das áreas reabilitadas no período compreendido entre 1979 e 1997 e os Relatórios de Transporte de Bauxita, no período compreendido entre janeiro e novembro de 1999 e os preços médios mensais da tonelada de bauxita seca, no período compreendido entre janeiro e novembro de 1999. Estes relatórios indicam a produtividade das minas em operação e diversas características do minério e indicam o número de viagens realizadas em cada corpo de minério e a transportadora.

\subsection{Análise de Dados}

A produção total de minério foi multiplicada pelos valores da venda para estimar a receita da CGM/Alcoa Alumínio S.A. Em seguida, foi calculado qual a porcentagem que os "gastos com reabilitação de áreas degradadas" representaram desta receita.

Este procedimento foi adotado em função da necessidade de relativização dos valores da receita da CGM/Alcoa Alumínio S.A. A empresa fornecedora de minério é do mesmo grupo da empresa compradora (ambas controladas pela Alcoa Alumínio S/A). Em função disso, a transação entre as empresas não está sujeita às leis de mercado, tornando a receita interna relativa.

A comparação, no final, buscou uma correspondência com a produção de bauxita, justamente para tentar minimizar os efeitos de dados financeiros viciados. É evidente que mesmo a indexação dos gastos com reabilitação de áreas degradadas em toneladas de bauxita não é plenamente satisfatória, mas possibilita a criação de um parâmetro de comparação temporal razoavelmente estável.

\section{RESULTADOS}

\subsection{Aspectos Legais}

\subsubsection{Considerações sobre a Constituição do Estado de Minas Gerais de 1989}

A Constituição do Estado de Minas Gerais de 1989 - CEMG/89 não se distancia da $\mathrm{CF} / 88$ quanto à proteção ambiental e competências. Assim, cabe ao 
Estado de Minas Gerais proteger o meio ambiente e legislar privativamente nas matérias de sua competência e, concorrentemente com a União, nas seguintes alíneas do inciso XV: f) florestas (...) conservação da natureza, defesa do solo e dos recursos naturais, proteção do meio ambiente e controle da poluição; g) (...) proteção do patrimônio paisagístico; h) responsabilidade por dano ao meio ambiente (...) e paisagístico (art. 10). A proteção ao meio ambiente e controle da poluição em qualquer de suas formas, a preservação das florestas, fauna e flora, assim como o acompanhamento e fiscalização das concessões de pesquisa e de exploração de recursos naturais são expressamente previstos como competência comum entre Estado, União e Município (art. 11, VI, VII e XI, respectivamente).

É facultado ao Procurador Geral de Justiça (Ministério Público) a iniciativa de Lei Complementar, que disponha sobre a manutenção de curadorias especializadas para atuação na defesa do meio ambiente (art. 125, IV). Os preceitos de proteção ambiental do art. $225 \mathrm{CF} / 88$, foram plenamente reafirmados pela CEMG/89. Algumas disposições especificamente aplicáveis à realidade regional podem ser encontradas no art. 250 e seus incisos (CEMG/89), que trata da Política Hídrica e Minerária do Estado.

A exploração de recursos naturais no território estadual e a responsabilidade por dano ambiental e poluição (art. 251) deve criar meios que permitam ao Município que se desenvolva em torno da atividade mineradora, diversificar sua economia, garantindo a permanência de seu desenvolvimento socioeconômico (arts 252 e 253). Alguns dispositivos dos referidos artigos não são auto-aplicáveis, dependendo de complementação.

\subsubsection{Considerações sobre a Lei Estadual de Minas Gerais $\mathbf{N}^{\mathbf{0}} \mathbf{7 . 7 7 2 / 8 0 ^ { 2 }}$}

A Lei 7.772/80 trata sobre a proteção, conservação e melhoria do meio ambiente, e no Decreto Estadual 39.424/98 (regulamentador da Lei em questão) é definido meio ambiente como sendo "o espaço onde se desenvolvem as atividades humanas e a vida dos animais e vegetais" $\left(\right.$ art. $2^{\circ}$ ). Neste espaço, assim definido, ocorre o que a lei entende por poluição ou degradação ambiental.

Poluição ou degradação ambiental é qualquer alteração das qualidades físicas, químicas ou biológicas do meio ambiente que possam prejudicar a saúde ou o bem estar da população; criar condições adversas às atividades sociais e econômicas; ocasionar danos relevantes à flora, à fauna e a qualquer recurso natural e ainda ocasionar danos, entre outros. Entende-se por fonte de poluição qualquer atividade, sistema, processo, operação, maquinaria, equipamento ou dispositivo, móvel ou não, que induza, produza ou possa produzir poluição; considerando-se agente poluidor qualquer pessoa física ou jurídica responsável por fonte de poluição (art. 2 ${ }^{\circ}$, Lei 7.772/80). Esta lei reforça e não fere os preceitos conceituais para o tema estabelecidos pela Lei Federal 6938/81 (art. $3^{\circ}$ ).

\footnotetext{
${ }^{2}$ Dispõe sobre a proteção, conservação e melhoria do meio ambiente.
} 
Há a necessidade de licenciamento (regulamentado pelo Decreto 39.424/98) ou autorização junto ao COPAM (cuja denominação Comissão de Política Ambiental foi alterada para Conselho Estadual de Política Ambiental pela Lei Estadual 9.514/87) para instalação, construção, ampliação ou o funcionamento de fonte de poluição no território de Minas Gerais (art. $8^{\circ}$ ). Portanto, os órgãos e entidades da Administração Estadual, e as Fundações vinculadas ao Estado, somente aprovarão projetos de instalação, construção e ampliação, ou o funcionamento de fonte de poluição, condicionados a estas condições, sob pena de nulidade dos seus atos.

A lei prevê a participação direta do Estado nas questões ambientais, clássico mecanismo de comando e controle (HADDAD e REZENDE, 2002). Além disso, incentiva os agentes econômicos a utilizarem meios ou tecnologias ambientalmente adequadas. O Estado pode conceder financiamentos, incentivos fiscais e ajuda técnica àqueles que, efetivamente, demonstrem a aplicação de equipamentos de controle da poluição, tratamento de efluente industrial ou de qualquer tipo de material poluente despejado ou lançado, e práticas de conservação de recursos naturais (art.14). Por outro lado, a Lei não incentiva a utilização de tecnologias melhores do que os padrões especificados, permitindo o despejo de resíduos que não excedam os limites estabelecidos pela autoridade competente (art. $3^{\circ} \mathrm{c} / \mathrm{c} 4^{\circ}$ do Decreto Estadual 39.424/98).

A Lei 7.772/80 também prevê infrações que, a critério do COPAM, podem ser classificadas em leves, graves ou gravíssimas, levando-se em conta: as suas conseqüências, as circunstâncias atenuantes e agravantes e os antecedentes do infrator (art.15). O Decreto 39.424/98 estabelece o procedimento administrativo para a aplicação da pena e elaboração das normas técnicas complementares, com critérios para a classificação das infrações, para a imposição de pena e para cabimento de recurso, respectivos efeitos e prazos de interposição.

As penalidades previstas pela Lei não excluem as cominações penais e cíveis cabíveis ao caso concreto (art.16 e Constituição Federal art.225, $\S 3^{\circ}$ ). As punições administrativas de que trata a Lei podem ser: advertência, não-concessão, restrição ou suspensão de incentivos físcais e de outros benefícios concedidos pelo Estado ou por empresa sob seu controle direto ou indireto; e suspensão das atividades. O Decreto 39.424/98 acrescenta que poderá também haver multa diária, até que o infrator corrija a irregularidade existente.

A Lei 11.903/95 criou a Secretaria de Estado de Meio Ambiente e Desenvolvimento Sustentável, atribuindo a este órgão a coordenação da Política Estadual (art. $4^{\circ}$, Lei 7.772/80).

A Lei 12.585/97 (alterada pelo Decreto Estadual 43.278/2003) dispunha, na época em que a pesquisa foi realizada, sobre a reorganização do COPAM, com competência, finalidades e estrutura. 


\subsubsection{Considerações sobre a Portaria 829/94 do Instituto Estadual de Florestas do Estado De Minas Gerais - IEF $^{3}$}

A previsão em nível federal de procedimentos de licenciamento ou autorização, não impedem que os Estados façam outras exigências. Nesta Portaria, é definido que os casos de licenciamento para exploração de área considerada de vocação minerária, dependem da aprovação do projeto técnico de recomposição da flora com espécies nativas locais ou regionais em complemento ao projeto de recuperação do solo, respeitando as normas do IEF e formalidades prévias do COPAM (art. $1^{\circ}$ ). Esta recomposição deve ser feita tanto em áreas de trabalhos de pesquisa quanto no desenvolvimento de lavra $\left(\operatorname{art} .7^{\circ}\right)$.

Os projetos mencionados não dispensam a compensação das áreas superficiais ocupadas com atividades mineradoras, suas instalações e servidões. É obrigatória a implantação, prioritariamente em locais vizinhos às áreas mineradas, de projetos de florestamento e reflorestamento, contemplando essências nativas regionais (art. $4^{\circ}$ ). A área de efetivo plantio será aquela resultante do somatório de todas as áreas mencionadas durante o processo de licenciamento (art. $5^{\circ}$ ).

Há previsão de obrigatoriedade da apresentação de um projeto de recomposição da flora em casos de atividades minerárias comprovadamente impactantes $\left(\operatorname{art} .8^{\circ}\right)$. A CF/88 informa que qualquer atividade minerária é impactante por sua própria natureza e como tal, exige-se a reparação dos danos ambientais. Unindo-se os dois textos, entende-se que o projeto específico de recomposição da flora referido nesta Portaria deve ser exigido para as atividades que a degradem precipitadamente, pois a degradação nos demais elementos da paisagem é inevitável e seguem a obrigatoriedade da Constituição Federal. Deve haver recuperação do dano, portanto, inclusive nas exceções de recomposição da flora (art. $8^{\circ}, \S 1^{\circ}$ ).

A análise do projeto técnico de recomposição da flora gera custos (emolumentos recolhidos em favor do IEF), designados pelo art. 10. Estes emolumentos variam de acordo com o tamanho do empreendimento: área inferior a 01ha é isento; área de 01 a 05ha são 05 UPFMG; área de 05,1 a 10ha são 10 UPFMG; área acima de 10 ha é 01 UPFMG por hectare.

\subsubsection{Considerações sobre o Papel do COPAM no Licenciamento Ambiental}

O COPAM foi instituído pelo Decreto Estadual 18.466/77, alterado pelas Leis Estaduais 7.772/87 e 12.585/97 e pelos Decretos Estaduais 39.490/98 e 43.278/03. Neste item serão abordados os aspectos legais da época em que a pesquisa foi realizada, excluindo-se, portanto, o Decreto Estadual 43.278/03 que será abordado nas considerações finais.

A Deliberação Normativa COPAM 30/98 estabelece seu regimento interno, ressaltando suas finalidades, competências e estrutura. Também foi estabelecido que

\footnotetext{
${ }^{3}$ Dispõe sobre normas específicas do IEF para aprovação do projeto técnico de recomposição da flora que vise o licenciamento da atividade minerária e dá outras providências.
} 
as decisões e Deliberações do COPAM estarão à disposição dos interessados e, também, que o Plenário reunir-se-á em sessão pública.

No Estado de Minas Gerais, o COPAM exerce papel de extrema importância nos procedimentos de licenciamento ambiental, normatização técnica e fiscalização. Este Conselho é órgão normativo, colegiado, consultivo e deliberativo, subordinado à Secretaria de Estado de Meio Ambiente e Desenvolvimento Sustentável (art. $2^{\circ}$, Lei Estadual 12.585/97).

Entre suas finalidades, destacam-se: deliberar sobre diretrizes, políticas, normas regulamentares e técnicas, padrões e outras medidas de caráter operacional, para preservação e conservação do meio ambiente e dos recursos ambientais, através das entidades a ela vinculadas e dos demais órgãos seccionais e locais (art. $3^{\circ}$, Decreto Estadual 43.278/03). Neste contexto, são considerados órgãos seccionais os órgãos ou as entidades da Administração Pública Estadual (ou as entidades municipais) cujas atividades estejam associadas às de proteção e controle do uso dos recursos ambientais (arts. $5^{\circ}$ e $6^{\circ}$ do Decreto Estadual $39.424 / 98$ e art. $3^{\circ}$ da Lei Estadual 12.585/97).

Os órgãos seccionais de apoio ao COPAM são: Fundação Estadual do Meio Ambiente (FEAM); Instituto Estadual de Florestas (IEF) e o Instituto de Gestão das Águas (IGAM). No caso específico da Câmara de Atividades Minerárias, o apoio e o assessoramento será feito pela FEAM, à qual compete, para o exercício de suas atividades: fiscalizar o cumprimento da legislação ambiental, instruir propostas de normas e processos de licenciamento e de infração, determinar realização de audiência pública em processos de licenciamento, decidir sobre concessão de LI e LO para atividades de pequeno porte ou pouco poluidoras/degradadoras, aplicar penalidades de suspensão de atividades e decidir sobre os pedidos de reconsideração referentes às penalidades por eles aplicadas (arts. 26, 27 e 28 do Dec. 39.490/98).

$\mathrm{O}$ art. $4^{\mathrm{o}}$ da Lei 12.585/97 define as competências do COPAM (c/c Lei 7.772/80 e Decretos Estaduais 39.424/98, 39.490/98 e 43.278/03), entre elas: aprovar relatórios de impacto ambiental; analisar, orientar e licenciar, por intermédio do Plenário, das Câmaras Especializadas e dos órgãos seccionais de apoio, no âmbito do Estado, a implantação e a operação de atividade efetiva ou potencialmente poluidora ou degradadora do meio ambiente, determinando igualmente a relocalização, a suspensão ou encerramento dessas atividades, quando necessário, ouvido o órgão seccional competente.

Observa-se que, valendo-se de sua autonomia, o Estado de Minas Gerais designou ao COPAM importantes atribuições, como aprovar relatórios de impacto ambiental, estabelecimento de normas e padrões ambientais, licenciamento e fiscalização ambiental, que serão exercidas por intermédio das Câmaras Especializadas.

A estrutura do COPAM, disposta no art. $8^{\circ}$ do Decreto 39.490/98, divide-se em: Presidência, Plenário, Câmaras Especializadas e Secretaria Executiva. A importância das Câmaras Especializadas na estrutura interna do COPAM, é denotada 
pela existência de uma Câmara de Assuntos Minerários (arts $8^{\circ}$, c, e 19 do Decreto 39.490/98). Esta Câmara, juntamente com a Câmara de Atividades Industriais e Câmara de Atividades de Infra-Estrutura, possui entre suas competências específicas: decidir sobre os pedidos de concessão de LP, LI, LO e Licenças de Instalação e Operação corretivas. Por fim, cabe ainda às mencionadas Câmaras, o requerimento ao Plenário, motivadamente, da aplicação das penalidades de suspensão de atividades (art. 16, III da Lei 7.772/80).

O Decreto 39.424/98 dispõe sobre os tipos de licenças ambientais existentes: LP, LI e LO (art. $9^{\circ}$ ). O Decreto 39.424/98 dispõe sobre os procedimentos administrativos para a concessão ou renovação de licenças (art. 10). Este assunto é tratado na Deliberação Normativa COPAM 13/95. O prazo para concessão das licenças previstas no mencionado art. $9^{\circ}$ é de seis meses (art. 11). Entretanto, na exigência da apresentação de EIA-RIMA, este prazo será de até doze meses (contados do protocolo de requerimento de licenciamento). Estes prazos podem ser alterados com motivação e anuência do empreendedor e do órgão licenciador. Os prazos de validade das licenças foram especificados na Deliberação Normativa COPAM 17/96.

O Decreto 39.424/98 também prevê o licenciamento corretivo para os casos onde os prazos para a concessão de LP e LI estejam vencidos (art. 12). Ainda assim, o interessado não está desobrigado à apresentação dos estudos ambientais cabíveis para a obtenção de LO.

Para estabelecimentos que utilizem recursos ambientais e seja considerado efetiva ou potencialmente poluidor (art. $8^{\circ}$, Decreto 39.424/98), os órgãos e entidades da Administração Estadual Direta e Indireta somente aprovarão projeto de implantação ou ampliação após o licenciamento, sob pena de responsabilização administrativa e nulidade de seus atos. No caso de concessão de incentivos fiscais ou financeiros, a empresa beneficiária deverá apresentar documento de licenciamento referido neste artigo, para a liberação dos recursos. A Resolução COPAM 1/92 e as Deliberações Normativas COPAM 3/93, 13/95 e 17/96 (estudadas mais adiante) também tratam de licenciamento, reforçando a importância do tema.

A fiscalização será exercida pelos órgãos seccionais de apoio ao COPAM, e seu procedimento está previsto no Decreto 39.424/98 (art. 14). A entrada dos agentes fiscalizadores nos estabelecimentos visitados (públicos ou privados) é assegurada, sendo possível ainda a requisição de apoio policial para a execução de fiscalização (art. 15).

Além das infrações já citadas, a art. 21 do Decreto 39.424/98 dispõe sobre a aplicação das penalidades de multa, definindo os valores por categoria de infração (leve, grave ou gravíssima), as circunstâncias atenuantes e agravantes das penas. Esta listagem é taxativa, e não exemplificativa. As multas também são tratadas pela Deliberação Normativa COPAM 27/98, analisada adiante.

É importante lembrar que as multas podem ter sua exigibilidade suspensa se o infrator firmar Termo de Compromisso aprovado pelo órgão ambiental que aplicou a 
penalidade, se obrigando voluntariamente à adoção de medidas reparadoras do dano (art. 21, $\S 2^{\circ}$ ).

Quando o empreendedor aplicar métodos ou sistemas para mitigação de danos ambientais ou poluição, contribuindo assim para a conservação dos recursos naturais, o Governo do Estado considerará estas práticas como fatores relevantes na concessão de estímulos em forma de financiamento, incentivos fiscais e ajuda técnica (Dec. 39.424/98, art.39).

\subsubsection{Considerações sobre Resoluções e Deliberações Normativas do COPAM: o Setor Minerário}

A Deliberação Normativa COPAM $1 / 89^{4}$ dispõe que as atividades de mineração que utilizem retroescavadeiras (prática comum na mineração de bauxita, pois a extração ou desmonte são realizados até $5 \mathrm{~m}$ de profundidade na região de Poços de Caldas) ou equipamentos afins, devem estar de acordo com as normas de controle ambiental $\left(\right.$ art. $\left.1^{\circ}\right)$.

A mesma Deliberação enseja a aplicação da Portaria 829/94 do IEF, obrigando a apresentação e aprovação de Plano de Recuperação de Área Degradada (PRAD) pela FEAM/COPAM, para o exercício de atividades de extração mineral e beneficiamento $\left(\operatorname{art} .7^{\circ}\right)$.

A Deliberação Normativa COPAM $1 / 90^{5}$ estabelece custos para análise de pedidos de licenciamento ambiental (LP, LI e LO), a serem previamente indenizados à FEAM pelo requerente. É importante ressaltar que nem só as licenças representam custos ambientais. Devem ser consideradas as despesas com elaboração de EIA/RIMA, Audiências Públicas, medidas de mitigação de impacto previstas no licenciamento, eventuais multas e, no caso da empresa em estudo, custos com empregados destinados a trabalhar em questões ambientais, além de investimentos voluntários da empresa em certificação ambiental.

As Deliberações Normativas COPAM 3/90 ${ }^{6}$ e 4/90 7 estabelecem, em maiores detalhes, os documentos necessários aos diferentes procedimentos de licenciamento ambiental, consoante a classe do mineral explotado e o tipo de licença requerida. $\mathrm{O}$ estudo detalhado destas normas pode fornecer elementos para estimativa dos custos legais envolvidos no licenciamento. De acordo com a Deliberação 3/90, a critério do COPAM, alguns empreendimentos podem ser dispensados do EIA/RIMA em função da sua natureza, localização, porte e demais peculiaridades. No entanto, é preciso destacar que normas estaduais podem ser apenas mais restritivas do que as federais, nunca mais brandas. A listagem de possibilidades de dispensa do EIA/RIMA proposta pelo COPAM ou qualquer órgão estadual, não podem ser mais amplas do

\footnotetext{
${ }^{4}$ Compatibiliza o exercício da atividade de extração e beneficiamento de minerais com a proteção ambiental.

${ }^{5}$ Estabelece os critérios e valores para indenização dos custos de análise de pedidos de licenciamento ambiental, e dá outras providências.

${ }^{6}$ Estabelece normas para o licenciamento ambiental das atividades de extração mineral da Classe II.

${ }^{7}$ Estabelece normas para o licenciamento ambiental das atividades de extração mineral das Classes I, III, IV, V, VI, VII, VIII e IX.
} 
que as preconizadas na esfera federal, sob pena de inconstitucionalidade desta dispensa (art. 225, $\S 2^{\circ} \mathrm{c} / \mathrm{c} \S 1^{\circ}, \mathrm{IV}, \mathrm{CF} / 88$ ).

A Resolução COPAM 1/92 trata dos instrumentos de controle do Sistema Estadual de Licenciamento de Fontes Poluidoras - SELF (LP, LI e LO). Na concessão da LP pelo COPAM, é necessária a apresentação de uma declaração da Prefeitura Municipal, informando que o local e o tipo de instalação estão conforme as leis e regulamentos administrativos do Município (vale neste caso o zoneamento). Além disso, a obtenção de LP ou LI não dispensa o interessado de apresentar os documentos cabíveis ao COPAM para a LO.

A Resolução COPAM 3/93 estabelece regras para a elaboração do Termo de Compromisso, visando à eliminação de condições degradadoras do meio ambiente. Este Termo de Compromisso e seu respectivo cronograma físico-financeiro, serão analisados pela FEAM e pela Câmara de Assuntos Minerários do COPAM.

A Deliberação Normativa COPAM 13/95 define a publicidade dos pedidos de licenciamento, renovações e concessões. $O$ requerente deve providenciar as publicações da concessão ou renovação de licenças, no prazo de 10 dias (contados do recebimento da notificação da decisão) em periódico local ou regional de grande circulação.

Nos termos da Deliberação Normativa COPAM $17 / 96^{8}$ a LP pode ser outorgada pelo COPAM por até 4 anos, a LI por até 6 anos e a LO por até 8,6 ou 4 anos dependendo da atividade (Anexo I da Deliberação Normativa COPAM 1/90). Estes prazos podem ser acrescidos de 2 anos (perfazendo o máximo de 8 anos de licenciamento) ou reduzidos em 2 anos (até o limite mínimo a ser respeitado, de 4 anos de duração do licenciamento, em casos de aplicação de penalidade prevista na legislação ambiental, transitada em julgado contra o concessionário). Os custos de análise do pedido de revalidação de licença podem variar entre 40 e $50 \%$ da LI e 70 e $100 \%$ da LO (Anexo I da Deliberação Normativa COPAM 1/90, nas classes I, II e III).

A Deliberação Normativa COPAM 27/98 dispõe sobre os valores das multas por infração ambiental de acordo com o porte do empreendimento e circunstâncias agravantes e atenuantes. $\mathrm{Na}$ maioria dos casos o valor final da multa não pode ultrapassar o limite máximo fixado nesta Deliberação (as exceções estão previstas no art. $21, \S 4^{\circ}$ do Decreto $39.424 / 98$ e nos casos de reincidência específica).

A Deliberação Normativa COPAM 29/98 estabelece critérios direcionados à atuação dos Municípios na esfera ambiental. Na fiscalização e licenciamento de atividades de impacto local, esta atuação será exercida através de convênios de entidades municipais e estaduais (SEMAD, FEAM, IEF e IGAM), em harmonia com os preceitos que regem o Sistema Nacional do Meio Ambiente - SISNAMA. A atuação municipal incidirá sobre atividades enquadradas nas Classes I, II e III simultaneamente, nas Classes I e II ou apenas na Classe I (Anexo I da Deliberação Normativa COPAM 1/90). O Município deverá optar por quais atividades ele irá

\footnotetext{
${ }^{8}$ Dispõe sobre o prazo de validade de licenças ambientais, sua revalidação e dá outras providências.
} 
licenciar e fiscalizar, mas sempre será ouvido em todas as etapas de licenciamento de atividades enquadradas em classes não especificadas no convênio (Município/Estado).

\subsubsection{A supressão da vegetação nas áreas de mineração}

A Deliberação Normativa COPAM $1 / 89^{9}$ sujeita à autorização do IBAMA, a supressão de vegetação para a prática de atividades minerárias $\left(\operatorname{art} .2^{\circ}\right.$ ). Complementarmente, a Deliberação Normativa COPAM 29/98 dispõe que, para empreendimentos que pressuponham a supressão de vegetação natural em área superior a 10ha, o licenciamento pelo Município conveniado com o Estado dependerá de parecer técnico favorável do IEF.

\subsection{Aspectos técnicos da reabilitação de áreas degradadas pela Alcoa Alumínio S.A.}

Diante do que foi exposto até o momento, cabe ressaltar três pontos principais: i) o licenciamento ambiental é procedido, em nível estadual, diante do COPAM; ii) o IEF exige, em caráter complementar ao EIA, os Planos de Recuperação de Áreas Degradadas (PRAD) e; iii) cabe ao IBAMA autorizar a supressão de cobertura vegetal em áreas superiores a 10 hectares, ou seja, em praticamente todas as áreas de mineração de bauxita da Alcoa Alumínio S.A. em Poços de Caldas.

A fim de cumprir com todas essas exigências, a empresa financia diversos grupos de pesquisa que trabalham com o desenvolvimento de métodos e técnicas de reabilitação de áreas mineradas.

Neste contexto, Coelho (1999) realizou estimativas de gastos para três diferentes estratégias de reabilitação com revegetação de áreas mineradas: com eucalipto, com tapete verde e com tapete verde combinado com espécies nativas. $\mathrm{O}$ custo total estimado para a revegetação com eucalipto, incluídos os custos operacionais e insumos era, na época, de $\mathrm{R} \$ 7.783,26 /$ ha. Para a revegetação com tapete verde, incluídos os custos operacionais e insumos, o valor total era de $\mathrm{R} \$$ $7.802,10 /$ ha. Por fim, o custo total estimado para a revegetação com tapete verde $e$ espécies nativas, incluídos os custos operacionais e insumos era de $\mathrm{R} \$ 12.989,59 / \mathrm{ha}$. Existem outros estudos financiados pela Alcoa Alumínio S.A. sobre o tema entre 1988 e 1999 (BALDASSARI, 1988; LORENZO, 1991; GISLER, 1995; SOUZA, 1997 e NAPPO, 1999).

\subsection{Estimativa de Gastos com Reabilitação de Áreas Degradadas}

Em relação aos gastos com combustíveis, o único recurso especificamente designado ao abastecimento de maquinário em reabilitação de áreas mineradas foi de US\$ 35,53 (em Novembro/99).

Os gastos com prestação de serviços por pessoas jurídicas foram maiores e melhor discriminados, totalizando, US\$128.946,70 no ano. Os gastos com

\footnotetext{
${ }^{9}$ Compatibiliza o exercício da atividade de extração e beneficiamento de minerais com a proteção ambiental.
} 
manutenção de veículos (mão de obra) totalizaram no ano US\$2.180,05. O único caso identificado de aquisição de peças automotivas para reparos, ocorreu em Outubro/99 no valor de US\$35,49. Os gastos empregados em fretes totalizaram US $\$ 28.577,58$, sendo aqui computado o transporte de terra vegetal nas áreas a serem reabilitadas. Em outras despesas, estão relacionados todos os gastos efetuados com revelação de filmes fotográficos durante 1999, com um total de US\$830,33. Os gastos efetuados com insumos, destinados a obras de reabilitação de áreas degradadas em 1999, totalizaram US\$14.332,53.

Os dados de controle de áreas reabilitadas possibilitaram o acompanhamento de todos os trabalhos de reabilitação de áreas mineradas realizados pela Alcoa Alumínio S.A. de 1979 até 1997. O mencionado controle fornece dados mais precisos para anos anteriores a 1997. Neste, de acordo com o relatório original, apenas uma área de 7,05ha havia sido reabilitada, na mina José Gabriel (Corpo de Minério 23.02). Esta área foi revegetada com eucalipto.

A produção total de bauxita seca entre janeiro e novembro de 1999 nas minas em operação (da Alcoa Alumínio S.A.) foi de 558.520,15t.

A receita total estimada através da produtividade das minas em operação, de janeiro a novembro de 1999, multiplicada pelo preço médio mensal da tonelada da bauxita seca, resultou em US\$1.868.136,00. Durante o mesmo período, o gasto total (estimativa) com reabilitação de áreas degradadas e atividades correlatas resultou em US\$174.938,21.

Com isso, conclui-se que os gastos com reabilitação de áreas degradadas pela CGM/Alcoa Alumínio S.A. representa aproximadamente $9,36 \%$ da receita proveniente da venda interna da produção.

\section{DISCUSSÃo}

Apesar do cálculo dos valores empregados por área minerada não ter sido efetuado por insuficiência de dados, foi possível identificar o custo da empresa para a reabilitação de área degradada como reflexo das exigências legais estudadas (repassados ao consumidor no preço final do produto). Mesmo considerando a imprecisão dos dados contábeis apurados, a produção de rejeitos na atividade é extremamente alta, o que leva à conclusão de que seria impossível reparar e/ou mitigar qualquer dano ambiental com US $\$ 0,50 / t$ de bauxita. Portanto, é possível afirmar com segurança que as estimativas de custos de reabilitação de área degradada da CGM estão abaixo da realidade e que na prática a empresa gasta muito mais.

Além disso, há a possibilidade legal de aplicação de várias multas (administrativas por descumprimento de exigências referentes ao procedimento de licenciamento e operação além das judiciais, em conformidade com a Lei de Crimes Ambientais, que prevê a responsabilidade penal da pessoa jurídica) dada a multiplicidade de órgãos ambientais envolvidos com a atividade. 
A intenção da legislação é promover a proteção ambiental em conjunto com o crescimento econômico. É preciso compatibilizar o art. 170 (da Ordem Econômica e Financeira) com o art. 225 (do Meio Ambiente) da CF/88. No entanto, o consumidor deve participar deste processo. O Código do Consumidor (Lei 8.078/90) exige a transparência das relações de consumo através da informação clara sobre os produtos disponibilizados no mercado (art. $4^{\circ}$, IV c/c art. $6^{\circ}$, III), inclusive sobre o processo produtivo (art. 55, $\S 1^{\circ}$ ). Portanto, é necessário informar os custos ambientais da empresa nas embalagens dos produtos, para que o consumidor possa optar pelo produto avaliando, entre outros critérios, os custos embutidos com proteção e reparação ambiental.

Conforme mencionado, resta salientar o que dispõe o Decreto Estadual 43.278/03 sobre a organização do Conselho Estadual de Política Ambiental COPAM. Este texto foi publicado após a realização da pesquisa, mas em linhas gerais, não alterando as competências (arts. $4^{\circ}, 23$ e 32). A modificação existente é a atribuição de competência ao COPAM para deliberar sobre pedidos de supressão de vegetação natural sujeitos a licenciamento ambiental (art. 24). Isto não exclui a necessidade de autorização perante o IBAMA, para áreas superiores a 10ha, sendo complementar ao licenciamento. Apesar de tramitar no mesmo órgão estadual, provocaria em tese custos adicionais por se tratar de outra Câmara Técnica (CT).

Merece destaque a discussão desenvolvida pelos grupos de trabalho do CONAMA sobre Áreas de Preservação Permanente. A CT Gestão Territorial e Biomas apresentou recentemente proposta de Resolução ${ }^{10}$ para a CT de Assuntos Jurídicos, dispondo sobre os casos excepcionais que possibilitam a supressão de vegetação e intervenção em APP.

$\mathrm{O}$ art. $2^{\circ}$ da proposta de Resolução dispõe que o Poder Público somente poderá autorizar a intervenção ou supressão de vegetação em APP, nos casos de utilidade pública e interesse social. O desenvolvimento de atividades de pesquisa e extração de substâncias minerais é um dos casos previstos de utilidade pública. O Ministério Público Federal apresentou proposta de emenda suprimindo este caso $\left(\operatorname{art} .2^{\circ}\right.$, I, alínea c) e, posteriormente, Ação Direta de Inconstitucionalidade (ADIN) perante o Supremo Tribunal Federal (STF). O STF concedeu liminar suspendendo o trâmite desta proposta de Resolução. Atualmente, a discussão do tema está sendo feita através de audiências públicas em todas as regiões do país.

A importância desta iniciativa é clara. Se a Resolução for aprovada com redação mais permissiva, surgiria a possibilidade de que empreendimentos minerários, como o caso apresentado neste texto, adentrem em áreas de preservação permanente. Isso significaria a supressão de vegetação e mineração de bauxita em topos de morro, comprometendo também a paisagem local, através da reformulação do relevo original em virtude do desmonte mecanizado.

\footnotetext{
${ }^{10}$ Procedência: 44a Reunião Extraordinária do CONAMA; Data: 23 e 24 de maio de 2005; Processo n $^{\circ}$ 02000.002382/2003-92; Assunto: Consolidação APP.
} 
Resta saber qual é a argumentação para considerar atividade de mineração como utilidade pública em detrimento da proteção ambiental. A normatização do CONAMA tem eficácia em todo o território nacional e a reparação dos impactos provocados depende da atividade desenvolvida e da resiliência do sistema no qual se insere. A diversidade ambiental do Brasil não permite generalizações desta magnitude, onde os aspectos regionais deveriam sobressair. A aprovação de norma desta natureza poderia acarretar prejuízos ambientais irreversíveis, tendo em vista o alto potencial de impacto da mineração.

\section{AGRADECIMENTOS}

Os autores agradecem ao Programa de Pós-Graduação em Direito Ambiental da UEA, à Secretaria de Estado de Ciência e Tecnologia do Amazonas, à Fundação de Amparo à Pesquisa do Estado do Amazonas, ao Programa de Pós-Graduação em Ecologia do Instituto Nacional de Pesquisas da Amazônia, ao Dr. Charles Ferreira (CGM/Alcoa Alumínio S/A.), pelo apoio financeiro, logístico e informações prestadas e aos referees, que proporcionaram o aprimoramento deste trabalho.

\section{REFERÊNCIAS}

BALDASSARI, I. B. Flora de Poços de Caldas: Família Melastomataceae. 1988. 265 f. Dissertação (Mestrado em Ciências Biológicas) - Instituto de Biologia, Universidade Estadual de Campinas, Campinas, 1988.

COELHO, R. A. Avaliação Custo Benefício de Estratégias Adotadas pela Alcoa Alumínio S.A. para Reabilitação de Áreas Degradadas pela Mineração de Bauxita em Poços de Caldas. 1999. 42 f. Monografia (Graduação em Agroecologia) - Escola Agrotécnica Federal de Machado - EAFM, Machado, 1999.

DESHPANDE, V. P.; SHEKDAR, A. V. Sustainable waste management in the Indian mining industry. Waste Manage. Res., n. 23, p. 343-355, 2005.

EYNON, G.; STEVENS, K. Instructional Case: ethical dilemmas in reporting environmental liabilities. Issues in Accounting Education, n.11, n.2, p. 393-417, 1996.

GISLER, C. V. T. O Uso da Serapilheira na Recomposição da Cobertura Vegetal em Áreas Mineradas de Bauxita, Poços de Caldas, MG. 1995.146 f. Dissertação (Mestrado em Ecologia) - Instituto de Biociências, Universidade de São Paulo, São Paulo, 1995. 
HADDAD, P.; REZENDE, F. Instrumentos Econômicos para o Desenvolvimento Sustentável da Amazônia.Brasília: Ministério do Meio Ambiente/Secretaria de Coordenação da Amazônia, 2002. 146 p.

HERRMANN, H. Política de aproveitamento de areia no Estado de São Paulo: dos conflitos existentes as compatibilizações possíveis. Rio de Janeiro: CETEM/CNPq, 1992.

HILSON, G.; POTTER, C. Structural Adjustment and Subsistence Industry: artesian gold mining in Ghana. Development and Change, Oxford, v.36, n.1, p. 103-131, 2005.

LIGHTBODY, M. Environmental auditing: the audit theory gap. Accounting Forum, Oxford, v.24, n.2, p. 151-169, jun. 2000.

LORENZO, J. S. Regeneração Natural de uma Área Minerada de Bauxita em Poços de Caldas, Minas Gerais. 1991. 151 f. Dissertação (Mestrado em Ciência Florestal) - Universidade Federal de Viçosa, Viçosa, 1991.

MACHADO, P. A. L. Direito Ambiental Brasileiro. 13. ed. São Paulo: Malheiros Editores, 2005. 1092 p.

MAS, R. F. US miners face tough future even with Bush in charge. American Metal Market, New York, 11 nov. 2002, p. 15.

NAPPO, M. E. Inventário Florístico e Estrutural da Regeneração Natural no Sub-Bosque de Povoamentos Homogêneos de Mimosa Scabrella Bentham, Implantados em Áreas Mineradas, em Poços de Caldas, Minas Gerais. 1999. 87 f. Dissertação (Mestrado em Engenharia Florestal), Universidade Federal de Lavras, Lavras, 1999.

PRADO FILHO, J. F.; SOUZA, M. P. O Licenciamento Ambiental da Mineração no Quadrilátero Ferrífero de Minas Gerais: uma análise da implementação de medidas de controle ambiental formuladas em EIAs/RIMAs. Eng. Sanit. Ambient. v.9, n.4, p. 343-349, dez. 2004.

SOUZA, J. A. de. Avaliação das Estratégias de Recuperação de Áreas Degradadas pela Mineração de Bauxita em Poços de Caldas (MG). 1997. 104 f.Tese (Doutorado em Agronomia) - Universidade Federal de Lavras, Lavras, 1997. 